This item was submitted to Loughborough's Research Repository by the author.

Items in Figshare are protected by copyright, with all rights reserved, unless otherwise indicated.

\title{
Incorporating persuasion into a decision support system: The case of the water user classification function
}

PLEASE CITE THE PUBLISHED VERSION

http://dx.doi.org/10.1109/IConAC.2016.7604957

PUBLISHER

(C) IEEE

VERSION

AM (Accepted Manuscript)

\section{PUBLISHER STATEMENT}

This work is made available according to the conditions of the Creative Commons Attribution-NonCommercialNoDerivatives 4.0 International (CC BY-NC-ND 4.0) licence. Full details of this licence are available at: https://creativecommons.org/licenses/by-nc-nd/4.0/

\section{LICENCE}

CC BY-NC-ND 4.0

\section{REPOSITORY RECORD}

Perren, Kim, Lili Yang, Jinjin He, Shuang-Hua Yang, and Yixing Shan. 2019. "Incorporating Persuasion into a Decision Support System: The Case of the Water User Classification Function". figshare. https://hdl.handle.net/2134/23704. 


\title{
Incorporating persuasion into a decision support system: the case of the water user classification function
}

\author{
Kim Perren, Lili Yang, Jinjin He, Shuang-Hua Yang \& Yixing Shan \\ Loughborough University, LE11 3TU, UK \\ L.Yang@lboro.ac.uk
}

\begin{abstract}
Utility stakeholders often view autonomic feedback systems as valuable tools for moderating consumption of household resources (e.g. electricity). However, to be successful, such technology must be not only informative but also persuasive. This paper presents the water user classification (WUC) function of a decision support system (DSS) for household water consumers. The function has been designed to harness powerful environmental norms in order to promote water conservation. It uses household appliance efficiency, water use routines and environmental values to attribute DSS users with a water user identity. Where this undermines their selfdefined identity as a 'green' consumer DSS users may be prompted to reevaluate their everyday practices. It also offers 'smart' personalized water saving advice. In this way, the WUC function aims to encourage consumers to adopt sustainable water saving behaviors. This paper describes the design of the WUC function and its contribution to the household DSS. It additionally highlights the crucial role of behavior change theory in the delivery of successful technology-based interventions.
\end{abstract}

Keywords-persuasive technology, household water conservation; water user identity; decision support system

\section{INTRODUCTION ${ }^{1}$}

In many regions of the world human activity is making unsustainable demands on fresh water resources. Where anthropogenic pressures lead to over-extraction from rivers, lakes and aquifers the aquatic environment may be degraded beyond repair. In addition, adequate fresh water supplies are crucial to everyday life; consequently, future economic and social wellbeing may be compromised by failure to enhance water security. In light of this, the European Union policy community has established the priority of moving toward a water-efficient and water saving economy [1]. A commitment to promoting a water saving culture is central to this approach.

Within the household, technological innovation has increased the efficiency of many domestic appliances; that is to say, the same (or higher) performance can be achieved with the consumption of less water than previously [2]. However, this potential saving may be negated by lifestyle changes associated with increasing prosperity and changing social norms; these include an increase in the number of end use sites (e.g. multiple bathrooms), demand for ever greater

${ }^{1}$ Funded by European Union's $7^{\text {th }}$ Framework Programme for Research and Technological Development under grant agreement 619228. performance (e.g. high volume power showers) and changes in water use habits (e.g. longer and more frequent showers). Consequently, the modification of water use behavior is a key component of any water demand management strategy.

The research presented in this paper derives from the household decision support system (DSS) module of the Integrated Support System for Efficient Water Usage and Resources Management (ISS-EWATUS) project. The DSS is a novel wireless system which monitors a household's water consumption disaggregated by appliance $[3,4,5]$. On the basis of spatio-temporal data retrieved, consumption feedback and advice (in the form of tips) is presented to the household, in near real time, via a mobile application (app). By increasing consumer awareness and promoting behavior change, the implementation of the DSS is conceptualized as a water demand reduction intervention measure. It is currently being trialed in 40 homes at sites in Poland and Greece.

The DSS design process melded expertise in the domains of software engineering, intervention design and social psychology [6,7]. Section II of this paper outlines how core behavior change strategies were incorporated into the design of autonomic DSS functions. It also identifies potentially valuable strategies which could only be operationalized by specifying additional functionality requiring user data entry. This was achieved via the WUC function which is described in Section III (data collection) and Section IV (classification and feedback). Section V offers a discussion of the critical role of behavior change theory in the design of effective persuasive technologies.

\section{BEHAVIOR CHANGE THEORY}

The design of the DSS took into account two essential characteristics of the intervention: 1) it aims to promote proenvironmental behavior and 2) it is ICT based. If a proenvironmental behavior change intervention is to have a meaningful impact, its outcome should be sustainable over the course of years or even a lifetime. With extended impact, however, comes the risk of annoyance. Consequently, a simple design which does not overwhelm the consumer with too much information but does require consumer participation is essential for the success of the intervention [8]. In the past, behavior change theory has been used successfully to guide 
goal attainment $[9,10]$, fill a knowledge gap [11], stimulate peer competition [12], and leverage social norms [13,14].

ICT-based behavioral intervention design has developed under the umbrella of "Persuasive Technology". This approach utilizes computing technologies to attempt to persuade users to change their attitude and behavior. It normally takes the form of an information system [15]. Since all information systems are designed to exert influence in some way, for a technology to be called "persuasive", the persuasion has to be intentional [16]; that is, the technology must have been designed for the purpose of guiding the user towards an attitude or behavior change. It follows from this that a desired (target) attitude or behavior has to guide the design process [17]. Numerous persuasive intervention strategies informed the functions that comprises the autonomic DSS; these are listed in this section (strategies A to G).

From a behavioral intervention perspective, one problematic issue with the autonomic functions of the DSS is that they cannot differentiate between the actions of different household members. In effect, the 'personalized' feedback and advice is not truly personal. A family may comprise a mix of careful and wasteful water consumers but all are presented with the same water consumption feedback. This lack of clarity about individual - as opposed to household consumption may limit a household member's appreciation of their own water using behavior and negatively affect their motivation to change.

A second issue is that there is a wealth of spatio-temporal water consumption data; however, there is a complete lack of information about the consumer's values, most saliently in the domain of water consumption. This limits the DSS's capacity to utilize two of the most powerful behavior change strategies; inconsistency and normative influence (see strategies $\mathrm{H}$ and I).

\section{A. Personalization}

The DSS supplies fine-grained feedback on water consumption in easy to comprehend graphical formats. Households can monitor consumption associated with individual appliances (e.g. washing machine and shower) and comparisons are available across days, weeks or months. This personalization can make people think that the system understands their situation and is working to help them achieve their goals [18]. Users offered personalized content are more likely to perceive the system, and the people behind it, to be trustworthy. In addition, when a system has the capability to tailor content, people will view it as smarter, boosting expertise perceptions.

\section{B. Goal setting and self-monitoring}

DSS users are encouraged to set their own water reduction target and monitor progress towards this goal. Goal setting and self-monitoring make it easier for people to know how well they are performing the target behavior, increasing the likelihood that they will continue $[15,18]$.

\section{Control}

The DSS produces information and advice (tips) on ways to reduce consumption which take account of the household's recent and historical water use patterns. This increases the user's sense of control over their water consumption.

\section{Ambient display}

Color can communicate specific information, the meaning of which depends on the situation or context [19]. Red primes the threat of a failure due to learned associations with threat advisory systems [20]. Several DSS functions incorporate color to subliminally influence users. For example, households who achieve their water reduction targets see their results in green (which has permissive connotations) whereas those whose consumption actually increases across the monitored period receive this information in red. Yellow (by implication, neutral) is used where consumption has deviated by less than $10 \%$ from the benchmark.

\section{E. Message framing}

It is theorized that gain-framed messages are most effective in promoting behaviors associated with safety and certainty, as people tend to avoid risks in the face of potential gains [21]. By contrast, a loss-framed message is most effective in promoting behaviors when involving potential risk because people are relatively open to taking risks when faced with potential losses. DSS tips are divided into two categories; gain-framed messages are presented with a green background while loss-framed ones have a red background.

\section{F. Expertise}

A system which is perceived to incorporate expertise will have increased powers of persuasion. The strategy of embodying expertise cues into an information system has been identified as a key principle for system credibility support [18]. A database of tips is embedded in the DSS to educate users on the environmental impact of water usage. Many tips demonstrate expertise (e.g. the cost of producing potable water).

\section{G. Real-world feel}

A system which highlights the people or the organization behind its content or services will have more credibility than one which does not. This is a key principle for information system credibility support [21]. The DSS provides information on the organizations which funded and conducted the development of the DSS.

\section{H. Inconsistency}

An established, effective strategy for inculcating behavior change is to evoke cognitive dissonance [22]. This occurs where individuals become aware that their actions are inconsistent with their core values; the ensuing sense of discomfort may prompt them to change their behavior. 


\section{Normative influence}

Perceived pressure to conform to social norms affects behavioral intention [23]. Social norms reflect the individual's beliefs about what peer groups would think of her/him for engaging (or failing to engage) in the target behavior. Domestic water consumption practices take place behind closed doors. As a consequence, consumers may assume their habits (e.g. taking a 30 minute shower) is reasonable when, in fact, society at large is likely to judge it as wasteful. The private nature of domestic water use shields users from normative influence.

The autonomic DSS functions cannot attribute water consumption to individual household members; information on values is not available; and the construction of feedback does not invoke social norms. The Water User Classification (WUC) function addresses these shortcomings by collecting information about water-related values and behaviors at individual level. Furthermore, the construction of a water user identity is based upon social, rather than individual, conceptions of desirable water-using behavior. This data collection exercise additionally permits the construction and provision of truly personalized (individualized) advice.

\section{WATER USER CLASSIFICATION DATA COLLECTION}

\section{A. Overview}

The WUC function constructs a water user identity and generates 'smart' tailored tips about potential water saving actions. Data are collected via a survey linked to the DSS app. Although only 40 households are involved in the DSS trial, the WUC function has been made more widely available through a separate social media module of the ISS-EWATUS project. In addition to the primary outcomes of water user identity and tips generation, it is recognized that these data can be analysed to provide insight into water consumer habits, perceptions and values.

The DSS app has been designed to be accessible from a mobile device and this assumption was adopted when the survey was developed. Each screen contains a single question, illustrated with a colorful graphic to enhance user appeal. Respondents are presented with 20 questions. In the interests of not overburdening them, the only socio-demographic characteristics collected are age and gender. Six questions relate to household technology and nine to the respondent's water use practices. The final three items address their environmental attitudes.

\section{B. Technology}

Technology questions collect information about the efficiency of the household's toilet(s) and showerhead(s) and whether the property is fitted with solar panels. While solar panels do not directly impact upon water consumption, it is proposed that their presence indicates a propensity to adopt resource-efficient technologies around the home. A related question asks how much consideration the household would give to buying a water- and energy efficient washing machine.

\section{Usage}

Respondents are asked about the frequency with which they take a shower or bath and the duration of a typical shower. They are also asked how long they would wear a pair of jeans or casual trousers (or skirt, if female) before putting the item in the laundry. They are asked a similar question for $\mathrm{T}$ shirts. Respondents are directed to report showering and laundry generation separately for winter and summer.

One usage question taps into user perceptions of nondiscretionary consumption. This asks, "If you were in a hurry, how quickly could you take a shower and still be adequately clean and presentable? How many minutes would you spend under the water?" Nondiscretionary consumption is the amount required to sustain everyday functions and is therefore (in the mind of the consumer) non-negotiable. The discretionary component denotes the amount which could be conserved by behaviour change alone (i.e. without attitude change). This question is used to generate a tip that highlights the amount of water which could be saved by routinely limiting showering to the nondiscretionary level.

\section{Environmental values}

There are three environmental questions with the response categories: strongly agree; mildly agree; unsure; mildly disagree and strongly disagree.

- $\quad$ The so-called environmental crisis facing humankind has been greatly exaggerated;

- Water pollution is a real problem for our rivers, lakes and coastal waters; and

- Over-extraction of water is damaging our groundwater, rivers and lakes.

\section{WATER USER CLASSIFICATION AND FEEDBACK}

Interventions which aim to reduce domestic water consumption differentiate between technological (efficiency) solutions and curtailment (limiting water use). Efficiency measures may entail a significant one-off expense (e.g. the replacement of an inefficient appliance) or short-term effort (e.g. buying and fitting tap aerators). By contrast, curtailment may entail inconvenience and require ongoing resolve, for example, routinely taking a short shower. People who are motivated to conserve water by environmental concerns may feel that they achieve their goal by engaging in one or other of these strategies.

The WUC function juxtaposes an individual's position on technological (efficiency), usage (curtailment), and environmental (value) dimensions. A water user identity is generated which incorporates the three dimensions and highlights where there is an inconsistency (i.e. where technology and/or user behavior is at odds with the consumer's values). Recognition of this should invoke 
uncomfortable cognitive dissonance and motivate users to modify their behavior and/or appliances.

The underlying rationale is that consumers who are concerned about the environment and have invested in efficient technologies may experience cognitive dissonance if they are attributed with the following water user identity:

\begin{abstract}
"You are a high tech/high use consumer. High tech households like yours save water and energy by adopting efficient technology $;$. . However, although you are very concerned about the environment, your everyday routines use a lot of water and energy : :."
\end{abstract}

Similarly, users who are use water wisely because they are concerned about the environment, but have inefficient appliances, may be discomforted to be told:

\section{"You are a careful but low tech environmentalist.}

Your frugal everyday routines help you to save water and energy $\odot$. . However, although you are very concerned about the environment, your home lacks the efficient technology that would help you save water and energy $:$ :."

\section{A. Classifying water users}

For the technology dimension, a count is undertaken with each of the following characteristics scoring one point (to a maximum of 4): one or more toilet is dual flush; one or more showerhead is water efficient; solar panels are installed; and the household would give a lot of consideration to buying a water- and energy-efficient washing machine. Users with a score of 2 or more are designated 'high tech' (HT); 1 is 'intermediate' (IT) and zero is 'low tech' (LT).

The usage dimension is a composite indicator of winter shower use and laundry generation. Information on summer habits is not used because of the differing climates at the two pilot sites (Mediterranean Greece and temperate Poland) and the theorized impact this would have on nondiscretionary water consumption. Up to five minutes per day indicates low shower usage; 6-11 minutes constitutes intermediate; 12 minutes or more is high. Wearing jeans/trousers/a skirt for five or more days is classed as low laundry usage; three or four days is intermediate; and one or two days is high. A low water user (LU classification) is both a low shower user and low laundry user. A high water user (HU classification) is either a high shower user or a high laundry user. All others are intermediate (IU).

TABLE I. DIMENSIONS OF USER CLASSIFICATION

\begin{tabular}{|l|l|c|c|}
\hline \multirow{2}{*}{\multicolumn{1}{|c|}{ Usage }} & \multicolumn{3}{c|}{ Technology } \\
\cline { 2 - 4 } & \multicolumn{1}{c|}{ High } & Intermediate & Low \\
\hline High & HTHU a, b, c & ITHU a, b, c & LTHU a, b, c \\
\hline Intermediate & HTIU a, b, c & ITIU a, b, c & LTIU a, b, c \\
\hline Low & HTLU a, b, c & ITLU a, b, c & LTLU a, b, c \\
\hline
\end{tabular}

For the environmental dimension, users are credited with a point each where they: strongly disagree that "The so-called environmental crisis facing humankind has been greatly exaggerated"; strongly agree that "Water pollution is a real problem for our rivers, lakes and coastal waters”; and strongly agree that "Over-extraction of water is damaging our groundwater, rivers and lakes”. A score of three identifies the respondent as an environmentalist (a) while a score of one or two identifies the respondent as environmentally aware (b). A score of zero is neither (c).

The columns in Table I identify the three classes of household technology: High tech (HT); Intermediate tech (IT) and Low tech (LT). The rows denote the three classes of water usage: High usage (HU); Intermediate usage (IU) and Low usage (LU). The nine cells thus derived each have three subclassifications. Suffix 'a' denotes 'environmentalist', 'b' is 'environmentally aware' and 'c' denotes neither of these.

\section{B. Construction of the water user identities}

Table II outlines the feedback components associated with the elements of Table I. The environmental dimension has a lesser status to the technological and usage dimensions. Ultimately, WUC survey respondents get positive feedback if they live in a high tech home or are frugal in their water use practices; they do not get validation for simply having proenvironmental attitudes. The environmental dimension is merely used as leverage where it is contradicted by the consumer's household technology or water usage.

Feedback is a composite of the components associated with the respondent's position on the three dimensions. For the primary dimensions of technology and water usage emojis clarify whether the feedback should be interpreted as positive (:) negative $(:)$ ) or neutral $(:)$.

TABLE II. FEEDBACK COMPONENTS

\begin{tabular}{|c|c|}
\hline & Feedback component \\
\hline High tech & $\begin{array}{l}\text { High tech households like yours save water and } \\
\text { energy by adopting efficient technology. :) }\end{array}$ \\
\hline Intermediate tech & $\begin{array}{l}\text { Your home lacks some simple technologies that } \\
\text { could help you save water and energy. :- }\end{array}$ \\
\hline Low tech & $\begin{array}{l}\text { Your home lacks the efficient technology that } \\
\text { would help you save water and energy. : }\end{array}$ \\
\hline $\begin{array}{l}\text { Environmentalist } \\
\text { (a) }\end{array}$ & You are very concerned about the environment. \\
\hline $\begin{array}{l}\text { Environmentally } \\
\text { aware (b) }\end{array}$ & $\begin{array}{l}\text { You are aware of environmental issues relating to } \\
\text { water consumption. }\end{array}$ \\
\hline $\begin{array}{l}\text { Environmentally } \\
\text { unaware (c) }\end{array}$ & $\begin{array}{l}\text { Compared with most people in Poland/Greece you } \\
\text { have a low level of awareness of environmental } \\
\text { issues. }\end{array}$ \\
\hline High usage & $\begin{array}{l}\text { Your everyday routines use a lot of water and } \\
\text { energy. : }\end{array}$ \\
\hline $\begin{array}{l}\text { Intermediate } \\
\text { usage }\end{array}$ & $\begin{array}{l}\text { Your everyday routines use too much water and } \\
\text { energy to make you a green consumer. }: ;\end{array}$ \\
\hline Low usage & $\begin{array}{l}\text { Your frugal everyday routines help you to save } \\
\text { water and energy. :- }\end{array}$ \\
\hline
\end{tabular}


TABLE III. USER LABELS

\begin{tabular}{|l|c|c|c|}
\hline \multirow{2}{*}{ Usage } & \multicolumn{3}{|c|}{ Technology } \\
\cline { 2 - 4 } & $\boldsymbol{H T}$ & \multicolumn{1}{c|}{ IT } & \multicolumn{1}{c|}{ LT } \\
\hline HU & $\begin{array}{c}\text { High tech/ } \\
\text { high use } \\
\text { consumer }\end{array}$ & High use consumer & $\begin{array}{c}\text { High use/ } \\
\text { low tech consumer }\end{array}$ \\
\hline IU & $\begin{array}{c}\text { Technology } \\
\text { focused } \\
\text { consumer }\end{array}$ & $\begin{array}{c}\text { Inactive } \\
\text { environmentalist (a) } \\
\text { Environmentally } \\
\text { aware but inactive } \\
\text { consumer (b) } \\
\text { Unconcerned } \\
\text { consumer (c) }\end{array}$ & Low tech consumer \\
\hline LU & $\begin{array}{l}\text { Green } \\
\text { environ } \\
\text { mentalist } \\
\text { (a) }\end{array}$ & $\begin{array}{l}\text { Careful } \\
\text { environmentalist (a) } \\
\text { Careful consumer (b } \\
\text { and c) }\end{array}$ & $\begin{array}{l}\text { Careful but low tech } \\
\text { environmentalist (a) } \\
\text { Careful but low tech } \\
\text { consumer (b and c) }\end{array}$ \\
\hline
\end{tabular}

Feedback begins with a label which locates users on the technology and usage dimensions (Table III). Where inclusion increases persuasiveness, labels also differentiate on the basis of the environmental dimension. Feedback components are concatenated using syntactically appropriate conjunctions. The label and associated description form a water user identity.

The results screen (Fig. 1) gives textual feedback and also graphically depicts the respondent's water user identity on the three dimensions. A color scheme is incorporated into the column and row headings to build upon the 'ambient display' behavior change strategy described previously. Low technology and high usage cells are colored red (implying risk); high technology and low usage cells are colored green (which suggests permission); intermediate cells are a neutral yellow. The emoji reflects whether the respondent has been identified as an environmentalist (:)), environmentally aware $(\otimes)$ or environmentally unaware $(:)$.

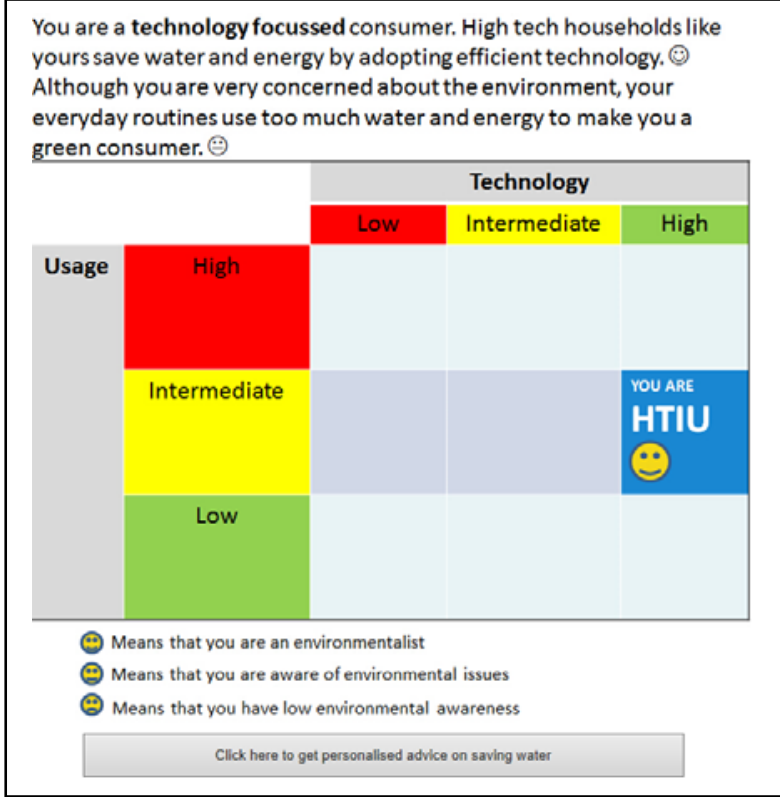

Fig. 1. Water User Classification Results Screen
Following on from this feedback, the WUC function presents the user with water-saving tips tailored to their water profile. This is the final screen of the WUC function. Tips which relate to showering take account of the reported efficiency of the showerhead. As described previously, respondents are asked the length of a typical winter shower (which is Question 10) and are also asked how quickly they could shower, if they were in a hurry (Question 11). Respondents who acknowledge that they could take a shorter shower are told:

"If you always took a [Question 11] minute shower instead of a [Question 10] minute shower you could save up to $[. .$.$] liters of water per month.”$

Where people do not acknowledge that they could take a shorter shower, and they take a winter shower which is at least seven minutes long, they are informed:

"If you reduced your shower by two minutes each time you could save up to [...] liters of water per month".

A high or intermediate laundry user would be told:

"You could save up to 2,500 liters of water per year by generating one less load of washing a week".

Where the respondent reports having inefficient appliances, simple modifications are advised, e.g.:

"A family of four with a conventional toilet could save 7,000 liters of water per year just by placing a water displacement device in their cistern”.

Even users who are highly conservative in their water use are offered tips which could help them in small ways, such as:

"Why not throw any water left in your cup onto an indoor plant rather than pouring it down the sink?”

\section{DISCUSSION}

Policy bodies across the world are committed to reducing the demands made upon freshwater resources and water distribution systems. For water stakeholders across a range of domains, autonomic monitoring and information systems are potentially invaluable tools for informing both efficiency strategies and behavioral interventions and for assessing results. However, in the domestic domain in particular, a system designed purely to monitor and inform is likely to have limited impact on measured water consumption across time. Rather, persuasion is a crucial third parameter.

The household decision support system module of the ISSEWATUS project has been tasked with developing a persuasive monitoring and information system and trialing it in a real world setting. As this paper has outlined, the design of 
the DSS has been founded upon key tenets of behavior change theory.

DSS sensors monitor water consumption; however, designers recognized that, for households, water consumption is a consequence of the enactment of everyday routines, such as showering, toilet flushing, and dishwashing. Consequently, information on consumption must be translated into component behaviors. These behaviors (rather than consumption, per se) became the target for the intervention. Autonomic feedback presents householders with consumption broken down by appliance and time. In so doing, it reveals the hidden water 'costs' of everyday routines. The feedback is accompanied by personalized advice on ways to modify these behaviors and thereby save water. The DSS also encourages consumers to set their own water consumption reduction goals and monitor their progress. This configuration addresses a potential information deficit and also empowers and motivates consumers.

The social context for domestic water use is incorporated into the autonomic functions of the DSS; for example, a color system is used to subliminally indicate 'risky' 'neutral' and 'safe' consumption trends. However, in the developmental stage, it was found that functions solely based upon spatiotemporal water consumption data could not capitalize on some of the most powerful behavioral intervention strategies. These centered on the core environmental values of the consumer and wider society. They included the promotion of cognitive dissonance and the use of social norms to assert leverage. In addition, the collection of spatio-temporal data at the household level may make it difficult for individuals to fully appreciate their own consumption.

The water user classification function has been designed to overcome these limitations. Unlike other DSS functions, this function requires users to input data. These relate to their household appliance efficiency, personal water using routines and environmental values. Compared with the remainder of the DSS, the WUC function is a low tech component; however, its contribution to the overall goal of achieving a sustained reduction in measurable consumption may be substantial. Its inclusion within the DSS highlights the overriding importance of identifying appropriate goals for behavioral interventions and adopting appropriate technologies to attain them.

\section{REFERENCES}

[1] COM (2007) 414 final. http://eur-lex.europa.eu/legalcontent/EN/TXT/?uri=CELEX:52007DC0414

[2] R. Critchley, and D. Phipps, Water and energy efficient showers. United Utilities, 2007.

[3] S.H. Yang, X.M. Chen, L. Yang, B. Chao and J. Cao, A Case Study of Internet of Things: a Wireless Household Water Consumption Monitoring System, IEEE WF-IOT 2015, Milan, Italy.

[4] N. Al-Hoqani and S.H. Yang, Adaptive Sampling for Wireless Household Water Consumption Monitoring, CCWI 2015, Leicester, UK, Procedia Engineering, pp. 1356-1365.
[5] X.M.Chen, S.H. Yang, L. Yang, and X. Chen, A Benchmark Model for Household Water Consumption Based on Adaptive Logic Networks, CCWI 2015, Leicester, UK, Procedia Engineering, pp. 1391-1398.

[6] K.Perren and L. Yang, Psychosocial and behavioural factors associated with intention to save water around the home: A Greek case study, CCWI 2015, Leicester, UK, Procedia Engineering, pp. 1447-1454.

[7] Y. Shan, L. Yang, K. Perren, and Y. Zhang, Household Water Consumption: Insight from a Survey in Greece and Poland, CCWI 2015, Leicester, UK, Procedia Engineering, pp.1409-1418.

[8] K. Ehrhardt-Martinez, K.A. Donnelly, and S. Laitner, Advanced metering initiatives and residential feedback programs: a meta-review for household electricity-saving opportunities. Washington, DC: American Council for an Energy-Efficient Economy, 2010.

[9] W. Abrahamse, L. Steg, C. Vlek, and T. Rothengatter, The effect of tailored information, goal setting, and tailored feedback on household energy use, energy-related behaviors, and behavioral antecedents. Journal of Environmental Psychology, 2007, 27(4), 265-276.

[10] C.M. Loock, T. Staake, and F. Thiesse, Motivating energy-efficient behavior with green IS: an investigation of goal setting and the role of defaults. Mis Quarterly, 2013, 37(4), 1313-1332.

[11] M. Weiss, C.M. Loock, T. Staake, F. Mattern, and E. Fleisch, Evaluating mobile phones as energy consumption feedback devices. In Mobile and Ubiquitous Systems: Computing, Networking, and Services, 2012 (6377). Springer Berlin Heidelberg.

[12] P. Petkov, F. Köbler, M. Foth, and H. Krcmar, Motivating domestic energy conservation through comparative, community-based feedback in mobile and social media. In Proceedings of the 5th International Conference on Communities and Technologies, 2011, (21-30). ACM.

[13] C. Grevet, J. Mankoff, and S.D. Anderson, Design and evaluation of a social visualization aimed at encouraging sustainable behavior. In System Sciences (HICSS), 2010 43rd Hawaii International Conference on (pp. 1-8). IEEE.

[14] J. Mankoff, S.R. Fussell, T. Dillahunt, R. Glaves, C. Grevet, M. Johnson, and L.D. Setlock, StepGreen. org: Increasing Energy Saving Behaviors via Social Networks. In ICWSM, May 2010.

[15] B.J. Fogg, Persuasive Technology: Using Computers to Change What We Think and Do. 2002, San Francisco: Morgan Kaufmann Publishers.

[16] R. Buchanan, Wicked problems in design thinking. Design issues, 1992, 5-21.

[17] J. Hamari, J. Koivisto, and T. Pakkanen, Do persuasive technologies persuade?-a review of empirical studies. In Persuasive Technology 2014 (pp. 118-136). Springer International Publishing.

[18] H. Oinas-Kukkonen and M. Harjumaa, Persuasive systems design: Key issues, process model, and system features. Communications of the Association for Information Systems, 2009, 24(1), 28.

[19] A.J. Elliot, M.A. Maier, A.C. Moller, R. Friedman, and J. Meinhardt, Color and psychological functioning: the effect of red on performance attainment. Journal of experimental psychology: General, 2007, 136(1), 154.

[20] M.S. Wogalter, V.C. Conzola, and T.L. Smith-Jackson, Research-based guidelines for warning design and evaluation. Applied ergonomics, 2002, 33(3), 219-230.

[21] A.J. Rothman and P. Salovey, Shaping perceptions to motivate healthy behavior: the role of message framing. Psychological bulletin, 1997, 121(1), 3.

[22] L. Festinger, A Theory of Cognitive Dissonance, 1957, Stanford University Press, Standford, California.

[23] I. Ajzen, The Theory of Planned Behavior, 1991, Organizational Behavior and Human Decision Processes, 50(2), 179-211. 